\title{
Roland E. Hester and Roy M. Harrison (Eds): Environmental Impacts of Road Vehicles. Past, Present and Future
}

\author{
Edward R. Adlard ${ }^{1}$
}

(c) Springer-Verlag GmbH Germany, part of Springer Nature 2018

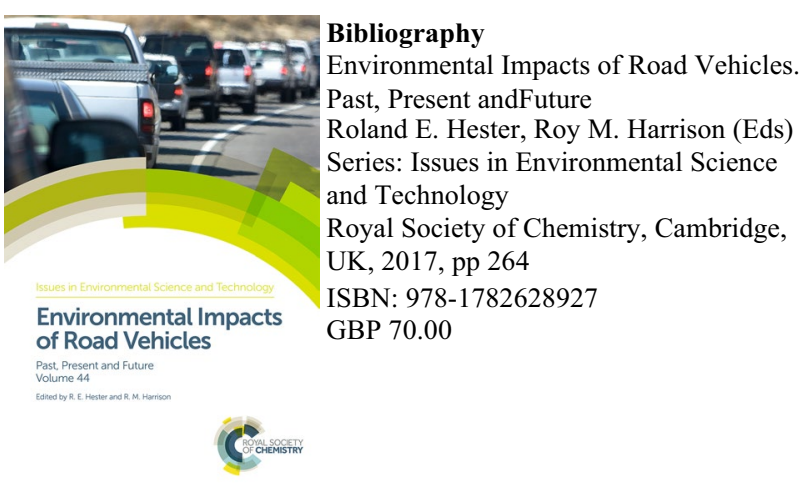

Road transport is one of the major contributors to $\mathrm{CO}_{2}$ emissions and as such is a concern unless it undergoes substantial changes. This book is number 44 of an RSC series on environmental issues and I note that some of the earlier volumes concern agriculture, another major contributor to $\mathrm{CO}_{2}$. Much has been, and is being done by the automotive industry in the way of hybrid and electric vehicles (which are covered in this book) but, to my knowledge, no one is considering an electrically powered combined harvester and aviation is likely to depend on fossil fuels permanently. In spite of these rather pessimistic thoughts, every little helps so reduction of road transport emissions is to be welcomed.

The book starts with an introductory survey and then moves on to the next chapter dealing with all the emissions from IC engines $\left(\mathrm{CO}_{2}, \mathrm{NO}_{x}\right.$ and particulates). In view of the recent concerns about manufacturer's claims this is particularly (no pun intended) relevant. The third chapter (it should be noted here that there are no chapter numbers in the book) deals in detail with IC engine emissions including such topics as the addition of various additives such as TEL and methyl cyclopentadiene manganese tricarbonyl (a new one to me). The fourth chapter is concerned with water and soil pollution and the next one is about the health effects of road traffic noise.

The later chapters consider future trends such as electric vehicles and the possibilities of hydrogen-fueled engines. The two final chapters deal with the end-of-life fate of vehicles and recycling.

Although this is a multi-author book, the editors have done an excellent job in welding it into a uniform whole. The book has wide appeal not only for the general reader but also for specialists such as environmentalists, petroleum chemists, engine designers and car manufacturers. As such it should find a ready market.
Edward R. Adlard

e.adlard77@btinternet.com

1 Burton, UK 